Original Research Paper

\title{
Effect of Platelet Rich Plasma on Post Cryopreservation Viability, Morphology and Proliferation of Human Umbilical Cord Stem Cells
}

\author{
${ }^{1,2}$ Noviyanti Goei, ${ }^{3,4}$ Isabella Kurnia Liem, ${ }^{3,5}$ Jeanne Adiwinata Pawitan and ${ }^{1,2}$ Dian Mediana \\ ${ }^{1}$ Biomedical Master Program, Faculty of Medicine, Universitas Indonesia, Jakarta, Indonesia \\ ${ }^{2}$ Department of Anatomy, Faculty of Medicine, Universitas Trisakti, Jl. Kyai Tapa, Jakarta, Indonesia \\ ${ }^{3}$ Stem Cell Medical Technology Integrated Service Unit, Cipto Mangunkusumo Central Hospital, \\ Faculty of Medicine, Universitas Indonesia, Jakarta, Indonesia \\ ${ }^{4}$ Department of Anatomy, Faculty of Medicine, Universitas Indonesia, Jakarta, Indonesia \\ ${ }^{5}$ Department of Histology, Faculty of Medicine, Universitas Indonesia, Jakarta, Indonesia
}

\section{Article history}

Received: $28-03-2015$

Revised: 20-05-2015

Accepted: 22-05-2015

Corresponding Author: Jeanne Adiwinata Pawitan Department of Histology,

Faculty of Medicine,

Universitas Indonesia, Jakarta, Indonesia

Email: jeanneadiwip@gmail.com

\begin{abstract}
In most cryopreservation medium, Fetal Bovine Serum (FBS) is used as supplement, while it is well known that FBS contains xenoproteins that can be incorporated into the cells and may be harmfull, as they can elicit immune response. Therefore, finding other xenofree materials as FBS alternative in cryopreservation medium is very important. Platelet Rich Plasma (PRP) is albumin rich and is a candidate for FBS alternative as cryopreservation supplement. Albumin is a natural extracellular cryoprotective agent that stabilizes impaired cell membrane during cryopreservation. This was an in vitro analytical study to to compare the effect of PRP and FBS as supplement in cryopreservation medium on human umbilical cord stem cells. In this study the stem cells were isolated from an umbilical cord tissue by explant method and propagated untill we got enough cells for cryopreservation. Cryopreservations were done using eight types of protocol, which differed in type and concentration of supplement and cell concentration. The effect of the eight protocols were compared in terms of post cryopreservation cell viability, morphology, cell size and proliferation. There were no difference between FBS and PRP supplemented cryopreservation media in term of cell viability and morphology. PRP supplemented medium showed better post cryopreservation performance in cell size and proliferation. PRP can be used as an alternative to FBS in cryopreservation medium for human umbilical cord tissue derived stem cells.
\end{abstract}

Keywords: Stem Cells, Umbilical Cord, Cryopreservation

\section{Introduction}

Stem cells are primitive cells that are endowed with self renewal capacity and can differentiate into other types of mature cells and thus is regarded as multipotent (Emil et al., 2005). Umbilical cord is a promising source of stem cells that have been attempted to cure various diseases since 1988. Umbilical cord as stem cell source has various advantages compared to other sources as it is easily collected from delivery waste, does not cause adverse effects to donor, devoid of ethical problems and the major advantage is its naive immune property, which may greatly reduce rejection problems (Goldstein et al.,
2007). Therefore, cryopreservation method is indispensable, if the stem cells are intended to be used for autologous or allogeneic cell therapy (Goldstein et al., 2007). However, there is no standardized cryopreservation method, especially for umbilical cord derived stem cells (Berz and Colvin, 2012).

There are various protocols for cryopreservation, which differ in the type and concentration of supplement and in cell concentration. These variables may have effects on post cryopreservation cell viability, morphology and proliferation capacity, when the cells are cultured in vitro. Moreover, some protocols use xeno material as supplement that may cause immune response (Mackensen et al., 2000) and 
stimulation of hapten formation (Martin et al., 2005). Therefore, finding xenofree supplement that is suitable for human umbilical cord derived stem cells is very important and platelet rich Platelet Rich Plasma (PRP) is a candidate (Pawitan, 2012). Murphy et al. (2012) found that PRP was an alternative supplement for murine cord blood derived mesenchymal stem cell cryopreservation.

However, there was no standardized supplement concentration for cryopreservation medium, though some protocols used 10 or $20 \%$. A study compared fibroblast viability after cryopreservation using various FBS concentrations, i.e., 0, 10, 20, 50 and $80 \%$ and found that 50 and $80 \%$ FBS caused decreased viability Falanga et al. (2004). Another study compared 40 and $70 \%$ FBS and found no significant difference in viability and recomended the use of $40 \%$ FBS (Nazarpour et al., 2012).

Cryopreservation protocols uses various cell concentrations, from $1 \times 10^{5}$ to $5.6 \times 10^{8}$ (Falanga et al., 2004; Simione, 2009; LTC, 2012; Meyer et al., 2006; Alencar et al., 2010; Rowley et al., 1994). Rowley et al. (1994) showed that a concentration of $5.6 \times 10^{8}$ was tolerable. Alencar et al. (2010) compared two concentrations, $1 \times 10^{8}$ and $2 \times 10^{8}$ cells $/ \mathrm{mL}$ and found no significant difference in viability. Meyer et al. (2006) showed that a concentration of $5 \times 10^{7}$ gave $89 \%$ viability.

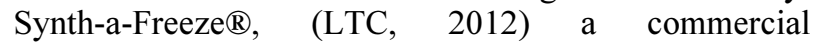
cryopreservation medium, recommends cell concentration $0.5-3 \times 10^{6}$ and Simione recommends stem cell concentration $10^{5}-10^{6}$ (Simione, 2009).

Therefore, this study aimed to compare the effect of 10 and $40 \%$ PRP and 10 and 40\% FBS as supplement in cryopreservation medium on human umbilical cord stem cells, using two cell concentrations of 100.000 and 500.000 cells $/ \mathrm{mL}$.

\section{Materials and Methods}

This was an experimental analytic in vitro study, which was done in Stem Cell Medical Technology Integrated Service Unit, Cipto Mangunkusumo Central Hospital-Faculty of Medicine Universitas Indonesia, from April through November 2014. This study got ethical aproval from the Ethical Commitee of the Faculty of Medicine, Universitas Indonesia (ethical clearance No.665/UN2.F1/ETIK/2014). Stem cells for this study were isolated using multiple harvest explant method (Pawitan et al., 2014) from an umbilical cord that was obtained from a Caesarean section delivery, after the woman signed the informed consent form. The cells were propagated untill passage 1 and 2 to get enough cells for cryopreservation experiments and upon subculture would become passage 2 and 3 .

\section{Comparison of Cryopreservation Protocols}

We compared eight protocols with variation in type of supplement (PRP and FBS), supplement concentration (10 and 40\%) and cell concentration (100,000 and $500,000$ cells $/ \mathrm{mL})$. The eight protocols can be seen in Table 1. All protocols contained final concentrations of 100U Penicillin/100 $\mu \mathrm{g}$ Streptomycin/mL (Biosera LM$\mathrm{A} 4118 / 100$ ) and $0.25 \mu \mathrm{g}$ Fungizone/mL (Gibco 15290018 ) in aMEM (Gibco 12000-014) as basal medium and $10 \%$ DMSO (Sigma D2650). The cells used were passage 1 and 2 cells with two replications each and therefore there were a total of 32 groups.

\section{Cryopreservation Procedure}

Cryopreservation was done by putting cell and cryopreservation medium containing cryotubes in $-20^{\circ} \mathrm{C}$ for $24 \mathrm{~h}$ and then the cryotubes were transfered to $196^{\circ} \mathrm{C}$ (in liquid nitrogen tank) for one month. After one month, the cryotubes were transfered to $37^{\circ} \mathrm{C}$ (in a water bath), to thaw the cells. Post thawed stem cells were checked for their viability and subcultured. Cultures of post thawed cells were compared to those of fresh cells. When the cells were $30 \%$ confluent, photographs were taken to observe their morphology and cell size that was represented by cell area was measured (in $\mu \mathrm{m}^{2}$ ) using Axiocam measuring program. Further, viability at harvest and Population Doubling Time (PDT) was calculated.

\section{Data collection and Analysis}

Data collected were post thawing and after culture cell-viability, cell size and PDT. When the data were suitable for parametric test, the differences in cell viability, size and PDT of post thawed cells between the eight protocols and fresh cells were analyzed using Analyses of Variance (ANOVA) from Statistical Product and Service Solution (SPSS) software version 16. However, when the data were not suitable, KruskalWallist test was used. Data of pre and post thawing were compared by paired t test (for parametric data) or Wilcoxon signed rank test (for non parametric data).

Table 1. Various cryopreservation protocols

\begin{tabular}{lllllllll}
\hline Protocol & 1(P10-100) & 2(P10-500) & 3(F10-100) & 4(F10-500) & $5(\mathrm{P} 40-100)$ & $6(\mathrm{P} 40-500)$ & $7(\mathrm{~F} 40-100)$ & $8(\mathrm{~F} 40-500)$ \\
\hline Suppl & PRP 10\% & PRP 10\% & FBS 10\% & FBS 10\% & PRP 40\% & PRP 40\% & FBS 40\% & FBS 40\% \\
Cell C & 100 & 500 & 100 & 500 & 100 & 500 & 100 & 500 \\
\hline
\end{tabular}

Suppl $=$ Supplement, PRP $=$ Platelet Rich Plasma, FBS $=$ Fetal Bovine Serum, Cell C $=$ Cell Concentration $/ \mathrm{mL}(\times 1000)$ 
Data from passage two and three were compared by independent $t$ test (for parametric data) or MannWhitney test (for non parametric data). When there was a significant difference, post hoc test was done to locate the difference.

\section{Results}

Post thawing cell counts were greatly reduced, especially in 100,000 cell concentration protocols (protocol 1, 3, 5 and 7). Therefore, viability tests were done on available remaining cells in each protocols.

\section{Cell Viability}

The medians of pre and post thawing cell-viability were 95.17 and $81.81 \%$ respectively and Wilcoxon test showed significant difference with a median difference of $13.36 \%$. However, Kruskal-Wallis test showed no significant difference in post thawing and after culture cell-viability between the eight protocols.

\section{Morphology and Cell Size}

Subcuture from fresh and post thawed cells of the eight protocols showed similar cell morphology that was fibroblastic (elongated and spindle shaped).

Median of cell size after culture in passage- 2 and passage-3 were $2464.5 \mu^{2}$ and $2072.19 \mu^{2}$ respectively and Mann-Whitney test showed a significant difference, with a median difference of $392.31 \mu^{2}$. Moreover, Kruskal-Wallis test of cell size after culture between the eight protocols and fresh cells showed no significant difference in passage-3 cells, but there were significant differences in passage2 cells between the eight protocols with fresh cells. Cell size of passage- 2 cells after culture from the eight protocols and fresh cells can be seen in Fig. 1. Differences in cell size and $\mathrm{p}$ value between the eight protocols and fresh cells can be seen in Table 2.

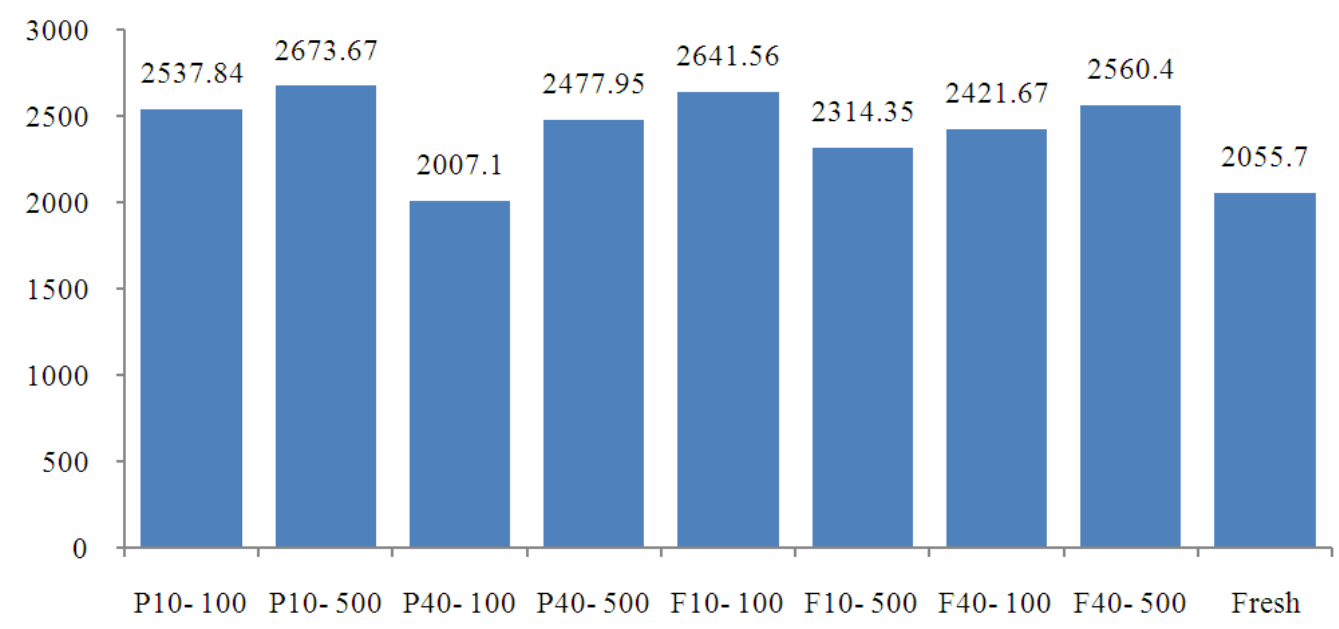

Fig. 1. Cell size after culture of passage-2 cells from the eight protocols and fresh cells

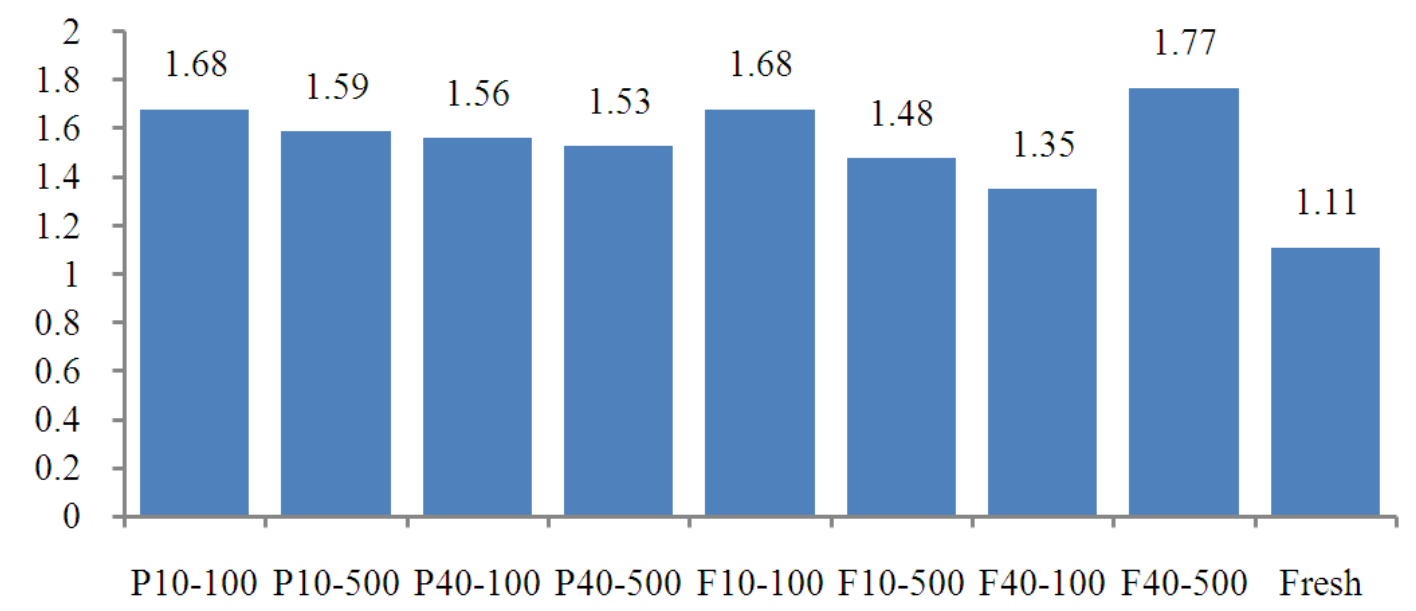

Fig. 2. PDT after culture of the eight protocols and fresh cells 
Table 2. $\mathrm{p}$ values of comparison of between fresh cell and the eight protocol cell size after culture of passage-2 cells

\begin{tabular}{llllllllll}
\hline Group & $\mathrm{A}$ & $\mathrm{B}$ & $\mathrm{C}$ & $\mathrm{D}$ & $\mathrm{E}$ & $\mathrm{F}$ & $\mathrm{G}$ & $\mathrm{H}$ & $\mathrm{I}$ \\
\hline $\mathrm{A}$ & & $0,532^{*}$ & $0,001^{*}$ & $0,954^{*}$ & $0,453^{*}$ & $0,189^{* *}$ & $0,718^{*}$ & $0,981^{*}$ & $0,004^{*}$ \\
& & $(135,83)$ & $(530,74)$ & $(59,89)$ & $(103,72)$ & $(261,2)^{*}$ & $(116,17)$ & $(22,56)$ & $(482,14)$ \\
$\mathrm{B}$ & $0,532^{*}$ & & $0,0001^{*}$ & $0,707^{*}$ & $0,836^{*}$ & $0,029^{*}$ & $0,312^{*}$ & $0,617^{*}$ & $0,002^{*}$ \\
& $(135,83)$ & & $(666,57)$ & $(195,72)$ & $(32,11)$ & $(359,32)$ & $(252)$ & $(113,27)$ & $(617,97)$ \\
C & $0,001^{*}$ & $0,0001^{*}$ & & $0,001^{*}$ & $0,0001^{*}$ & $0,077^{*}$ & $0,003^{*}$ & $0,002^{*}$ & $0,441^{*}$ \\
& $(530,74)$ & $(666,57)$ & & $(470,85)$ & $(634,46)$ & $(307,25)$ & $(414,57)$ & $(553,3)$ & $(48,6)$ \\
D & $0,954^{*}$ & $0,707^{*}$ & $0,001^{*}$ & & $0,665^{*}$ & $0,103^{*}$ & $0,637^{*}$ & $0,693^{*}$ & $0,004^{*}$ \\
& $(59,89)$ & $(195,72)$ & $(470,85)$ & & $(163,61)$ & $(163,6)$ & $(56,28)$ & $(82,45)$ & $(422,25)$ \\
E & $0,453^{*}$ & $0,836^{*}$ & $0,001^{*}$ & $0,665^{*}$ & & $0,025^{*}$ & $0,260^{*}$ & $0,336^{*}$ & $0,001^{*}$ \\
& $(103,72)$ & $(32,11)$ & $(634,46)$ & $(163,61)$ & & $(327,21)$ & $(219,89)$ & $(81,16)$ & $(585,86)$ \\
F & $0,189^{*}$ & $0,029^{*}$ & $0,077^{*}$ & $0,103^{*}$ & $0,025^{*}$ & & $0,197^{*}$ & $0,172^{*}$ & $0,277^{*}$ \\
& $(261,2)^{*}$ & $(359,32)$ & $(307,25)$ & $(163,6)$ & $(327,21)$ & & $(107,32)$ & $(246,05)$ & $(258,65)$ \\
G & $0,718^{*}$ & $0,312^{*}$ & $0,003^{*}$ & $0,637^{*}$ & $0,260^{*}$ & $0,197^{*}$ & & $0,832^{*}$ & $0,019^{*}$ \\
& $(116,17)$ & $(252)$ & $(414,57)$ & $(56,28)$ & $(219,89)$ & $(107,32)$ & & $(138,73)$ & $(365,97)$ \\
H & $0,981^{*}$ & $0,617^{*}$ & $0,002^{*}$ & $0,693^{*}$ & $0,336^{*}$ & $0,172^{*}$ & $0,832^{*}$ & $(138,73)$ & $0,020^{*}$ \\
& $(22,56)$ & $(113,27)$ & $(553,3)$ & $(82,45)$ & $(81,16)$ & $(246,05)$ & $(138,73)$ & $(504,7)$ \\
I & $0,004^{*}$ & $0,002^{*}$ & $0,441^{*}$ & $0,004^{*}$ & $0,001^{*}$ & $0,277^{*}$ & $0,019^{*}$, & $0,020^{*}$ & $(504,7)$ \\
& $(428,14)$ & $(617,97)$ & $(48,6)$ & $(422,25)$ & $(285,86)$ & $(258,65)$ & $(365,97)$ & $(504)$ \\
\hline
\end{tabular}

$*=$ Mann- Whitney test, ${ }^{* *}=$ independent t- test, $(\mathrm{)})$ cell size median diffeence, ()$^{*}=$ cell size mean difference, A: PRP $10 \%$ and cell concentration 100,000, B: PRP 10\% and cell concentration 500,000, C: PRP 40\% and cell concentration 100,000, D: PRP 40\% and cell concentration 500,000, E: FBS $10 \%$ and cell concentration 100,000 , F: FBS $10 \%$ and cell concentration 500,000, G: FBS $40 \%$ and cell concentration 100,000 , H: FBS $40 \%$ and cell concentration 500,000, I: fresh cells

Table 3. $\mathrm{p}$ values of comparison of between fresh cell and the eight protocol PDT after culture

\begin{tabular}{|c|c|c|c|c|c|c|c|c|c|}
\hline Group & A & $\mathrm{B}$ & $\mathrm{C}$ & $\mathrm{D}$ & $\mathrm{E}$ & $\mathrm{F}$ & $\mathrm{G}$ & $\mathrm{H}$ & I \\
\hline \multirow[t]{2}{*}{$\mathrm{A}$} & & $0,363^{* *}$ & $1,000^{*}$ & $0,126^{*}$ & $0,500^{*}$ & $0,062^{* *}$ & $0,155^{* *}$ & $0,268^{* *}$ & $0,12^{*}$ \\
\hline & & $(0,1)^{*}$ & $(0,12)$ & $(0,15)$ & (0) & $(0,2)^{*}$ & $(0,2)$ & $(0,24)^{*}$ & $(0,57)$ \\
\hline \multirow[t]{2}{*}{ B } & $0,363^{* *}$ & & $0,680^{*}$ & $0,262^{*}$ & $0,186^{*}$ & $0,177^{* *}$ & $0,378^{* *}$ & $0,051^{* *}$ & $0081^{*}$ \\
\hline & $(0,1)^{*}$ & & $(0,03)$ & $(0,06)$ & $(0,09)$ & $(0,1)^{*}$ & $(0,1)^{*}$ & $(0,34)^{*}$ & \\
\hline \multirow[t]{2}{*}{$\mathrm{C}$} & $1,000^{*}$ & $0,680^{*}$ & & $0,376^{*}$ & $0,157^{*}$ & $0,160^{*}$ & $0,201^{*}$ & $0,483^{*}$ & $0,149^{*}$ \\
\hline & $(0,12)$ & $(0,03)$ & & $(0,03)$ & $(0,12)$ & $(0,08)$ & $(0,21)$ & $(0,21)$ & $(0,45)$ \\
\hline \multirow[t]{2}{*}{ D } & $0,126^{*}$ & $0,262^{*}$ & $0,376^{*}$ & & $0,015^{*}$ & $0,861^{*}$ & $0,934^{*}$ & $0,023^{*}$ & $0,106^{*}$ \\
\hline & $(0,15)$ & $(0,06)$ & $(0,03)$ & & $(0,15)$ & $(0,05)$ & $(0,18)$ & $(0,24)$ & $(0,42)$ \\
\hline \multirow[t]{2}{*}{ E } & $0,500^{*}$ & $0,186^{*}$ & $0,157^{*}$ & $0,015^{*}$ & & $0,006^{*}$ & $0,095^{*}$ & $0,867^{*}$ & $0,044^{*}$ \\
\hline & (0) & $(0,09)$ & $(0,12)$ & $(0,15)$ & & $(0,2)$ & $(0,33)$ & $(0,09)$ & $(0,57)$ \\
\hline \multirow[t]{2}{*}{$\mathrm{F}$} & $0,062^{* *}$ & $0,177^{* *}$ & $0,160^{*}$ & $0,861^{*}$ & $0,006^{*}$ & & $0,981^{* *}$ & $0,019^{* *}$ & $0,153^{*}$ \\
\hline & $(0,2)^{*}$ & $(0,1)^{*}$ & $(0,08)$ & $(0,05)$ & $(0,2)$ & & $(0)^{*}$ & $(0,44)^{*}$ & $(0,37)$ \\
\hline \multirow[t]{2}{*}{ G } & $0,155^{*}$ & $0,378^{*}$ & $0,201^{*}$ & $0,934^{*}$ & $0,095^{*}$ & $0,981^{* *}$ & & $0,118^{* *}$ & $0,351^{*}$ \\
\hline & $(0,2)^{*}$ & $(0,1)^{*}$ & $(0,21)$ & $(0,18)$ & $(0,33)$ & $(0)^{*}$ & & $(0,44)^{*}$ & $(0,24)$ \\
\hline \multirow[t]{2}{*}{$\mathrm{H}$} & $0,268^{* *}$ & $0,051^{* *}$ & $0,483^{*}$ & $0,023^{*}$ & $0,867^{*}$ & $0,019^{* *}$ & $0,118^{* *}$ & & $0,021^{*}$ \\
\hline & $(0,24)^{*}$ & $(0,34)^{*}$ & $(0,21)$ & $(0,24)$ & $(0,09)$ & $(0,44)^{*}$ & $(0,44)^{*}$ & & $(0,66)$ \\
\hline \multirow[t]{2}{*}{ I } & $0,12^{*}$ & $0,081^{*}$ & $0,149^{*}$ & $0,106^{*}$ & $0,044^{*}$ & $0,153^{*}$ & $0,351^{*}$ & $0,021^{*}$ & \\
\hline & $(0,57)$ & $(0,48)$ & $(0,45)$ & $(0,42)$ & $(0,57)$ & $(0,37)$ & $(0,24)$ & $(0,66)$ & \\
\hline
\end{tabular}

*= Mann- Whitney test, ${ }^{* *}=$ independent $\mathrm{t}$ - test, $\left(\mathrm{)}=\right.$ PDT median difference, ()$^{*}=$ PDT mean difference, A: PRP $10 \%$ and cell concentration 100.000 , B: PRP $10 \%$ and cell concentration 500.000 , C: PRP $40 \%$ and cell concentration 100.000 , D: PRP $40 \%$ and cell concentration 500.000 , E: FBS $10 \%$ and cell concentration 100.000 , F: FBS $10 \%$ and cell concentration 500.000 , G: FBS $40 \%$ and cell concentration 100.000 , H: FBS $40 \%$ and cell concentration 500.000, I: fresh cells

\section{Population Doubling Time}

The PDT after culture of the eight protocols and fresh cells can be seen in Fig. 2. Kruskal-Wallis test showed significant diffence in PDT after culture of the eight protocols and fresh cells. Differences in PDT and $\mathrm{p}$ value between the eight protocols and fresh cells can be seen in Table 3 .

\section{Discussion}

In this study, there was a significant decrease $(13.36 \%)$ in the median of pre and post thawing cell viability from 95.17 to $81.81 \%$. Post thawing cell viability in this study was relatively higher compared to the study of Polchow et al. (2012) which found that post thawing viability was not more than $70 \%$. The 
difference might be due to different source of cryopreserved cell, as Polchow et al. (2012) used human vascular umbilical cord cells. Another study by Ginis et al. (2012) found post thawing cell viability of 72 and $80 \%$ using 5 and $10 \%$ DMSO containing cryopreservation medium respectively, (Ginis et al., 2012) which was similar to our result.

In this study, there was no significant difference in post thawing and after culture cell-viability between the protocols that used FBS and PRP. This fact suggests that PRP is equivalent in preserving post thawing cell viability to FBS.

In this study, after culture cell morphology for cryopreserved cells was fibroblastic (elongated and spindle shaped), similar to the findings of other studies (Polchow et al., 2012; Baksh et al., 2007; Secco et al., 2008; Xiang et al., 2007). We did not find any clusters of cells with endothelial appearance/cobblestone like, which might be due to the cryopreserved cell source that were from passage- 1 and passage- 2 .

Morphology of cryopreserved cells using PRP and FBS supplement was similar and this result was in line with the findings of other studies (Polchow et al., 2012; Xiang et al., 2007). This fact suggests that PRP is equivalent in preserving post thawing cell morphology to FBS.

A study by Scheers et al. (2013) showed increase in cell size with increasing passage, which was supposed as cell aging and therefore it was suggested that small cells were preferable. However, there was no published study that measured cell size.

Cryopreserved cell size after culture showed that cells from passage-3 were significantly smaller compared to those from passage-2, with a median difference of $392.31 \mu \mathrm{m}$. This fact might be due to increasing homogeneity with increasing passage, as was found by two studies on mesenchymal stem cells (Doan et al., 2012; Liem et al., 2014).

Cryopreserved cell size after culture of protocol P40100 cells were significantly smaller compared to those of P10-500, P40-500, F10-100, F40-100 and F40-500 and this fact suggested that PRP $40 \%$ as supplement was better in preserving cryopreserved cell size after culture.

Fresh cells from passage- 2 were smaller compared cryopreserved cells of protocol P10-100, P10-500, P40500, F10-100, F40-100 and F40-500 after culture. This finding was different from Bahadori et al. (2009) findings that found cryopreserved MSC morphology after culture was similar until passage- 9 and increase in size happened after passage-10, where the cells became flatten and large that indicated aging (Bahadori et al., 2009). In this study, increase in cryopreserved cell size after culture might be due to the property of some viable cells from passage- 2 that loss their ability to attach and proliferate, so that seeding of 5000 cells $/ \mathrm{cm}^{2}$ was in fact far smaller and therefore needed more population doubling to become confluent. Moreover, cryopreserved cell concentration in Bahadori et al. (2009) study was $10^{6} \mathrm{cells} / \mathrm{mL}$ that caused decrease in DMSO concentration at seeding compared to this study.

In this study, increase in proliferation rate was in line with decrease in proliferation doubling time. Proliferation doubling time in protocol P40-500 that was smaller compared to those of F10-100 and F40-500 showed that PRP $40 \%$ was better than FBS $40 \%$ and cell concentration of 500.000 was better than 100.000 in preserving cryopreserved cell proliferation.

A study found no difference in proliferation rate between cryopreserved and fresh MSCs, (Vasconcelos et al., 2012) while another study found higher proliferation rate in cryopreserved compared to fresh cells that was supposed to be due to cell selection (Ginis et al., 2012). In our study, PDT of fresh cells was significantly smaller compared to cryopreserved cells in protocol F10-100 and F40-500. Higher proliferation rate in fresh cells might be due to cryopreservetion injury that was endured by cryopreserved cells due to DMSO and very low cooling effect compared to fresh cells that were relatively intact (Gao and Critser, 2000).

Lower proliferation rate of cryopreserved cells in this study might be due to our cryopreservation procedure that did not use slow cooling method. In our study, we put the cell and cryopreservation medium containing cryotubes in $-20^{\circ} \mathrm{C}$ for $24 \mathrm{~h}$ and then the cryotubes were directly transfered to $-196^{\circ} \mathrm{C}$, while other studies used slow cooling method (Ginis et al., 2012; Vasconcelos et al., 2012).

Greatly reduced cell number after washing step after thawing may cause problems, if cryopreservation is intended to keep the cells for later use. Moreover, too low cell count might cause bias in viability testing and this fact was the limitation of our study.

\section{Conclusion}

Platelet rich plasma can be used as FBS substitute in cryopreservation medium and the use of PRP $40 \%$ and higher cell concentration is recommended.

\section{Acknowledgement}

We are indebted to all staff of Stem Cell Medical Technology Integrated Service Unit, Cipto Mangunkusumo Central Hospital-Faculty of Medicine Universitas Indonesia, PT. Kimia Farma and Cellsafe who has assisted in maintaining the lab facility and sample collection. Finally, we would like to appreciate the donor who donated the umbilical cord tissue. 


\section{Funding Information}

This study was funded by a grant from the Department of National Education of the Republic of Indonesia (PUSNAS 2014, contract number: 2218/H2.R12/HKP.05.00/2014).

\section{Author's Contributions}

Noviyanti Goei: Laboratory activities, data collection and analysis, writing the article in Indonesian, final approval.

Isabella Kurnia Liem: Developing the idea, consultant, revising the article, final approval.

Jeanne Adiwinata Pawitan: Developing the idea, supervising laboratory activities, revising and translating the article, final approval.

Dian Mediana: Laboratory activities, proof reading the article, final approval.

\section{Ethics}

This study was approved by the Ethical Commitee of Faculty of Medicine Universitas Indonesia-ethical clearance No.665/UN2.F1/ETIK/ 2014.

\section{References}

Alencar, S., M. Garnica, R.R. Luiz, C.M. Nogueira and R. Borojevic et al., 2010. Cryopreservation of peripheral blood stem cell: The influence of cell concentration on cellular and hematopoietic recovery. Transfusion, 50: 2402-2412. DOI: $10.1111 / j .1537-2995.2010 .02743 . x$

Bahadori, M.H., B. Soltani, E. Mirzajani, P. Babaei and M.M. Ansar et al., 2009. Cryopreservation of rat bone marrow derived mesenchymal stem cells by two conventional and open-pulled straw vitrification methods. Yakhteh Med. J., 11: 317-326.

Baksh, D., R. Yao and R.S. Tuan, 2007. Comparison of proliferative and multilineage differentiation potential of human mesenchymal stem cells derived from umbilical cord and bone marrow. Stem Cells, 25: 1384-1392. DOI: 10.1634/stemcells.2006-0709

Berz, D. and G. Colvin, 2012. Cryopreservation of Hematopoietic and Non-Hematopoietic Stem Cells-a Review for the Clinician. In: New Advances in Stem Cell Transplantation. Demirer, T. (Ed.), InTech, Croatia, ISBN: 10-978-953-51-0013-3, pp: 231-266.

Doan, C.C., N.H. Truong, N.B. Vu, T.T., Nguyen and H.M. Nguyen et al., 2012. Isolation, culture and cryopreservation of human bone marrow- derived mesenchymal stem cells. Inter. J. Plant Anim. Environ. Sci., 2: 83-90.
Emil, A.M., K. Hanna and K. Gebbie, 2005. Cord Blood: Establishing a National Hematopoietic Stem Cell Bank Program. 1st Edn. National Academies Press, Washington DC, ISBN: 10-0309165172, pp: 334.

Falanga, J., D. Fiore, N. Kouttab, C. Paiva and P. Carson, 2004. Viability and apoptosis of wound fibroblasts after cryopreservation. WOUNDS, 9: 283-287.

Gao, D. and J.K. Critser, 2000. Mechanisms of cryoinjury in living cells. ILAR J., 41: 187-196. DOI: 10.1093/ilar.41.4.187

Ginis, I., B. Grinblat and M.H. Shirvan, 2012. Evaluation of bone marrow-derived mesenchymal stem cells after cryopreservation and hypothermic storage in clinically safe medium. Tissue Eng. Part C Methods, 18: 453-463.

DOI: $10.1089 /$ ten.tec.2011.0395

Goldstein, G., A. Toren and A. Nagler, 2007. Transplantation and other uses of human umbilical cord blood and stem cells. Curr. Pharm. Des., 13: 1363-1373. DOI: 10.2174/138161207780618759

Liem, I.K., D. Wulandari, E. Budiyanti and J.A. Pawitan, 2014. Flow cytometry analysis of umbilical cord derived-stem cell cultured in various Xeno-free media. Proceedings of the 18th Congress of the International Federation Associations of Anatomists, Aug. 8-10, Beijing, China.

LTC, 2012. Synth-a-Freeze ${ }^{\circledR}$, cryopreservation medium. Life Technologies Corpor.

Mackensen, A., R. Dräger, M. Schlesier, R. Mertelsmann and A. Lindemann, 2000. Presence of IgE antibodies to bovine serum albumin in a patient developing anaphylaxis after vaccination with human peptide-pulsed dendritic cells. Cancer Immunol. Immunother., 49: 152- 156.

DOI: $10.1007 / \mathrm{s} 002620050614$

Martin, M.J., A. Muotri, F. Gage and A. Varki, 2005. Human embryonic stem cells express an immunogenic nonhuman sialic acid. Nat. Med., 11: 228-232. DOI: $10.1038 / \mathrm{nm} 1181$

Meyer, T.P.H., B. Hofman, J. Zaisserer, V.R. Jacobs and B. Fuchs et al., 2006. Analysis and cryopreservation of hematopoietic stem and progenitor cells from umbilical cord blood. Cytotherapy, 8: 265-276. DOI: $10.1080 / 14653240600735685$

Murphy, M.B., D. Blashki, R.M. Buchanan, I.K. Yazdi and M. Ferrari et al., 2012. Adult and umbilical cord blood-derived platelet-rich plasma for mesenchymal stem cell proliferation, chemotaxis and cryopreservation. Biomaterials, 33: 5308-5316. DOI: 10.1016/j.biomaterials.2012.04.007

Nazarpour, R., E. Zabihi, E. Alijanpour, Z. Abedian and H. Mehdizadeh et al., 2012. Optimization of human Peripheral Blood Mononuclear Cells (PBMCs) cryopreservation. Int. J. Molecular Cellular Med., 1: 88-93. PMC: 3920500. 
Pawitan, J.A., 2012. Platelet rich plasma in xeno-free stem cell culture: the impact of platelet count and processing method. Curr. Stem. Cell Res. Ther., 7: 329-335. DOI: 10.2174/157488812802481508

Pawitan, J.A., I.K. Liem, E. Budiyanti, I. Fasha and L. Feroniasanti et al., 2014. Umbilical cord derived stem cell culture: Multiple-harvest explant method. Int. J. PharmTech Res., 6: 1202-1208.

Polchow, B., K. Kebbel, G. Schmiedeknecht, A. Reichardt and W. Henrich et al., 2012. Cryopreservation of human vascular umbilical cord cells under good manufacturing practice conditions for future cell banks. J. Trans. Med., 10: 1-17. DOI: $10.1186 / 1479-5876-10-98$

Rowley, S.D., W.I. Bensinger, T.A. Gooley and C.D. Buckner, 1994. Effect of cell concentration on bone marrow and peripheral blood stem cell cryopreservation. Blood, 83: 2731-2736.

Scheers, I., C. Lombard, M. Paganelli, D. Campard and M. Najimi et al., 2013. Human umbilical cord matrix stem cells maintain multilineage differentiation abilities and do not transform during long-term culture. PLOS One.

DOI: 10.1371/journal.pone.0071374
Secco, M., E. Zucconi, N.M. Vieira, L.L. Fogaça and A. Cerqueira et al., 2008. Multipotent stem cells from umbilical cord: cord is richer than blood. Stem Cells, 26: 146-150.

DOI: $10.1634 /$ stemcells.2007-0381

Simione, F.P., 2009. Thermo scientific nalgene and nunc cryopreservation guide.

Vasconcelos, R.G., R.A. Ribeiro, M.G. Vasconcelos, K.C. Lima and C.A. Barboza, 2012. In vitro comparative analysis of cryopreservation of undifferentiated mesenchymal cells derived from human periodontal ligament. Cell Tissue Banking, 13: 461-469. DOI: 10.1007/s10561-011-9271-3

Xiang, Y., Q. Zheng, B. Jia, G. Huang and Y. Xu et al., 2007. Ex vivo expansion and pluripotential differentiation of cryopreserved human bone marrow mesenchymal stem cells. J. Zhejiang Univ. Sci. B. 8: 136-46. DOI: 10.1631/jzus.2007.B0136 